\title{
Problems and promises of innovation: why healthcare needs to rethink its love/hate relationship with the new
}

\author{
Mary Dixon-Woods, ${ }^{1}$ Rene Amalberti, ${ }^{2}$ Steve Goodman, ${ }^{3}$ Bo Bergman, ${ }^{4}$ \\ Paul Glasziou ${ }^{5}$
}

${ }^{1}$ Department of Health Sciences, Adrian Building, University of Leicester, Leicester, UK

${ }^{2}$ Haute Autorite de Sante (HAS), Saint Denis-La Plaine, France

${ }^{3}$ Division of Biostatistics, Johns Hopkins School of Medicine, Baltimore, Maryland, USA

${ }^{4}$ Centre for Healthcare Improvement, Chalmers University of Technology, Gothenburg, Sweden ${ }^{5}$ Director of the Centre for Research in Evidence-based Practice, Faculty of Health Sciences and Medicine, Bond University, Headington, UK

Correspondence to Professor Mary

Dixon-Woods, Department of Health Sciences, Adrian Building, University of Leicester, Leicester LE1 7RH, UK; md11@le.ac.uk

Accepted 9 October 2010

This paper is freely available online under the BMJ Journals unlocked scheme, see http://qualitysafety.bmj. com/site/about/unlocked. xhtml

\section{ABSTRACT}

Innovation is often regarded as uniformly positive. This paper shows that the role of innovation in quality improvement is more complicated. The authors identify three known paradoxes of innovation in healthcare. First, some innovations diffuse rapidly, yet are of unproven value or limited value, or pose risks, while other innovations that could potentially deliver benefits to patients remain slow to achieve uptake. Second, participatory, cooperative approaches may be the best way of achieving sustainable, positive innovation, yet relying solely on such approaches may disrupt positive innovation. Third, improvement clearly depends upon change, but change always generates new challenges. Quality improvement systems may struggle to keep up with the pace of innovation, yet evaluation of innovation is often too narrowly focused for the system-wide effects of new practices or technologies to be understood. A new recognition of the problems of innovation is proposed and it is argued that new approaches to addressing them are needed.

\section{INTRODUCTION}

Innovation in healthcare can take many forms, ranging from drug therapies, surgical procedures, devices and tests, through to new forms of health professional training, patient education, and management, financing and service delivery models. 'Innovation' is widely assumed to be positive in its effects, to the extent that the term 'innovative' usually expresses unqualified praise. In this paper, we seek a critical reappraisal of the role of innovation in quality improvement in healthcare. Using a range of disciplinary perspectives (rather than offering an extensive literature review), we identify the tradeoff problems associated with innovation, and we challenge practitioners, organisations and institutions to recognise and confront the paradoxes of innovation.

\section{FIRST PARADOX OF INNOVATION: UPTAKE OF THE DUBIOUS, REJECTION OF THE GOOD}

The first paradox of innovation is the wellknown problem that some new practices enjoy rapid uptake and diffusion throughout health systems, even when they are of limited benefit or unproven efficacy, or represent risks to patients, while other innovations that could secure better outcomes for patients never make it to the bedside.

The reasons why unproven innovations are sometimes rapidly adopted and implemented are becoming better understood. ${ }^{1}$ Some are rather like consumer fads - a new technology or therapy generates the excitement of newness and 'must-have'-even before the evidence base has been firmly established. For example, percutaneous bladder neck suspension for stress incontinence was initially hailed as a great success and came into widespread use, but subsequent longterm follow-up of trials showed very disappointing outcomes. ${ }^{2}$ Some innovations diffuse rapidly because they offer hope in otherwise intractable or desperate situations where denying an available therapy is difficult. Examples include the use of laetrile for cancer, which, despite its enthusiastic promotion during the 1970s, lacked evidence of effectiveness - and indeed there is some evidence of toxicity. ${ }^{3}$ Some innovations are adopted and implemented because they have considerable face validity or intuitive appeal as plausible solutions, but later turn out to be wrong. Well-known examples include the use of antiarrhythmic agents in the treatment of myocardial infarction, and human albumin in treatment of critically ill patients. $^{4}$ Organisations may also adopt innovations as a defence against anxiety, to guard against criticism that any failing was 
due to non-adoption. The widespread use of early warning scores and rapid response teams for deteriorating patients, despite only very equivocal evidence of benefit, ${ }^{5}$ may be an example of this.

The uptake of many dubious interventions relies on a form of magical thinking, where doing something is seen as better than doing nothing. The language used to promote innovations can be strongly implicated in such thinking. Terms such as 'breakthrough,' 'radical,' 'new' and even 'innovative' can stimulate consumer instincts, including those related to anticipated decision regret-where patients (and doctors) are reluctant to turn down any chance of possible improvement, even if there is only a small chance of success. ${ }^{6}$

Of course, rapid diffusion of innovation is also driven by profit-seeking behaviour. The engines of innovation may be commercial organisations prepared to resort to inventing 'diseases' (such as social anxiety disorder), repackaging cheap treatments as expensive ones for new markets (eg, using an expensive form of the cheap colon cancer drug Avastin for treating macular degeneration) or bringing to market technologies that offer only limited advantages over existing treatments. Many new devices-particularly diagnostic ones-need do no more than demonstrate that they comply with basic safety standards, and produce no evidence of efficacy. But organisations that stand to profit from the use of a new intervention may use sophisticated and aggressive marketing strategies, often enlisting patient pressure along the way and pressing political buttons to garner support. Clamour for therapies from desperate patients can be difficult to resist, as every health system in the world has discovered. Once institutions have invested in a new intervention, they then have a vested interest in recovering the costs, as the example of proton beam therapy for prostate cancer shows.

Diffusion of innovation without proven efficacy introduces several threats to quality improvement. Most obviously, such innovation may pose risks to patients. More insidiously, the deflection of effort and investment is a huge opportunity cost for health systems that undermines efforts to improve services. Further, the innovation may disrupt or displace procedures in areas that have been targets of quality improvement.

A mirror image to the problem of innovations without proven efficacy is the failure of diffusion of innovations that are of proven value. Here again, the evidence about what causes some efficacious innovations to remain unwrapped in the box is emerging. Some innovationsfor example, pelvic floor exercises or improved hand hygiene practices-have little of the glamour of new technologies and generate little excitement. Others require a level of investment, training or reinforcement that healthcare organisations or practitioners may struggle to achieve. Some are simply tedious and inconvenient, or threaten existing interests. Many lack a well-funded advocate with access to modern marketing techniques and budgets; when there is no manufacturer who stands to profit, promotion may be lacklustre. Some fall victim to the problem that when there are plenty of areas where coercive forces are at work (eg, targets or standards against which performance will be rewarded), the spotlight naturally slips off those that are not the focus of such measures.

The appeal of the new and the rejection of the dull cannot be explained by focusing solely on individual and organisational behaviours. Complex systemic processes and institutional forces are at work. For example, decisions about which clinical research is done and which is published (and where) are implicated in determining whether an intervention ever comes to attention, what kinds of attention it gets and whether it gets adopted or implemented. Publication bias, which causes interventions to appear more useful than they really are, is just one of these systemic effects.

\section{SECOND PARADOX OF INNOVATION: THE WISDOM AND FAILINGS OF DEMOCRACY}

The second paradox of innovation is that one of the most effective ways of ensuring the implementation of new technologies, therapies and techniques is by working cooperatively with the professional groups expected to engage in implementing it, but relying solely on cooperation may also be the most effective way of killing an innovation.

Theoretical work on participatory governance has drawn on Charles Lindblom's arguments about the 'intelligence of democracy' to emphasise the benefits of involving those likely to be affected by change and with relevant knowledge in decisions about innovation and implementation. ${ }^{7}$ Participatory, collaborative forms of decision-making and action may not only enable better informed decisions but also foster social learning and more sustainable outcomes, unite and motivate those with a commitment to solving problems, increase the chances of detecting the potential for innovation, and improve people's willingness to accept change. ${ }^{8}$ There is now increasing recognition of, and excitement about, the role of self-organising, self-governing networks in securing desirable outcomes in healthcare and elsewhere. ${ }^{9-12}$ Within healthcare, there has been particular interest in using a social movements approach as an alternative to programmatic approaches that emphasise centrally led, planned programmes of change. Social movements are characterised by their self-directing nature, their use of informal systems and the self-management of change. ${ }^{13}$ 
Such approaches may be especially promising in their ability to address well-known problems of attempts to change practice among professionals, who may strongly prefer to take their 'directions for performance' from within rather than outside their professional group $^{14}$ and be capable of subverting administrative fiats and managerial instructions. ${ }^{15} 16$ Social movements and other forms of community-based participatory approaches, with their emphasis on cooperation and norms of reciprocity, may be more likely to enable collaborative activity to be maintained long term, ${ }^{17}$ and thus promote sustainability of innovation. The strengths of such approaches to professional work are reinforced by their continuities with longstanding collegial structures, and the corresponding centrality of the community principle in the organisation and experience of professional work. $^{18}$

However, the counter to the 'wisdom of democracy' is the failings of democracy. Group-based, cooperative efforts may be undermined by those who fail to engage with, or commit to, the collaborative activity, and by the risk that individuals will substitute their own goals for those of the group, so that the collaboration is undermined by individual or group interests. ${ }^{18}$ Professional boundaries, particularly between different disciplines and occupational groups, may create barriers to proper collaboration. Social movements can become sites of struggle and contestation, and may never succeed in fully delivering their aims. For instance, the evidence-based medicine (EBM) movement, including the founding of the Cochrane Collaboration, can be understood as a social movement ${ }^{19}$ that sought to respond to the problem we identified in Paradox 1: that some treatments known to work are ignored, and other treatments not shown to work get used. Though this particular social movement has enjoyed enormous success, Paradox 1 has not disappeared, and the command of EBM over the hearts and minds of many clinicians has been, at best, partial.

Some of the reasons for variable success of participatory, grass-roots approaches lie in the difficulties of creating arenas and opportunities for clinicians to collaborate and the antagonism of bureaucratic and professional structures to so doing. These are important problems, since those leading and managing networks must elicit support through building coalitions and forging agreement, sometimes in the face of local opposition or inertia, ${ }^{20}$ as well as creating environments where productive, goal-directed relationships and interactions are most likely to occur. They must also be able to manage the changing nature of the collaborative effort over time, and address the risk that collaborations may start out with considerable enthusiasm, but gradually develop less helpful features including competition and rivalry between different members of the network, fragmentation or duplication of effort, emergence of disruptive hierarchies, or diminishing commitment and ability to secure resources. ${ }^{17}$ Professional groups are themselves susceptible to persuasion and manipulation by commercial forces-either directly or indirectly-that may undermine their ability to behave in the interests of the public good. If innovation is to be managed appropriately in healthcare, there is an urgent need to find approaches that can combine the benefits of cooperative, participatory approaches with other regulatory techniques.

\section{THIRD PARADOX OF INNOVATION: HEALTH SYSTEMS ARE NEVER ABLE TO KEEP UP}

The third paradox of innovation is that improvement requires change, but change always generates new challenges. Quality improvement systems are rarely able to keep pace with innovation; innovation disrupts. For example, the rise of stenting procedures by cardiologists means that many patients previously managed by cardiothoracic surgeons (bypass surgery) are now being cared for by different personnel in different physical configurations of healthcare settings, and thus a whole new set of quality challenges arises. Further, people improvise, change their habits and reconfigure their work practices in response to new technologies, often in unpredictable ways. ${ }^{21}$ By the time quality-assurance systems have caught up with the 'new' modality, things have already moved on yet again. Having a cycle of renewal and reinvention creates ongoing organisational turbulence and may diminish organisational and practitioner enthusiasm for quality improvement.

This problem is intensified by the ongoing failure of the dominant evaluation paradigm. This continues to confine evaluation narrowly to the intervention that is the direct focus of the evaluation, rather than considering the systemic effects and unintended consequences of interventions. For instance, a typical evaluation seeking to assess whether a new technique for monitoring patients at risk of critical illness will tend to determine the effects of the technique only for that class of patients. The risks the system introduces elsewhere (such as the impact of prioritising monitoring over other goals of healthcare) thus remain unknown. Social science work is needed alongside intervention studies not only to help assess unintended consequences, but also to provide vital evidence about issues relating to adoption, implementation and optimisation in different contexts. 


\section{CONCLUSION: ADDRESSING THE PROBLEMS OF INNOVATION}

Rationality is a contested concept in the social sciences, but perhaps the most influential approach derives from the work of psychologists Tversky and Kahnemann, who specify rationality in terms of consistency and coherence. ${ }^{22}$ Defined in that sense, the paradoxes we have outlined help to explain why it makes little sense to think of rationality as the main driver of innovation in health systems. Non-rational collective decisions should perhaps be considered the norm rather than the outlier: when health systems are faced with continual external and internal pressures for innovation combined with strong emotional, economic and political forces, the ability of those systems to engage in rational debate and planning is undermined. Yet the need to avoid unnecessary innovations and manage the transition for necessary innovations is among the most important challenges facing health systems today.

If a new technology or technique is being considered for use, health systems should consider the principles of quality improvement as they are introduced rather than waiting for the inevitable problems to occur (box 1). Thus, for a new surgical procedure, we might ask:

i. What is the evidence that the procedure improves outcomes in other settings, while recognising the complexities of generalisation? ${ }^{23}$

\section{Box 1 Innovation in healthcare: an agenda for action}

- Recognise the risks and costs of innovation, including the disruptive effects even of beneficial innovation.

- Have more effective systems for controlling the diffusion of innovation, including better systems for accrediting use of technologies (not simply approval of the product/ device).

- Study innovation at the same time as it is occurring, and collect data to link new interventions to outcomes (both intended and unintended).

- Run adoption and implementation studies using highquality social science methods and theory alongside trials; do not wait until the trial is complete before working out what is needed to adopt and implement the intervention in real life.

- Clarify lines of authority in relation to innovation and use institutional authorities to mediate and adjudicate between the competing interests and demands of frontline actors, patients and their advocates, and manufacturers.

- Use the clinical trial model of Phase I studies to identify the potentially unwanted or unhelpful effects of innovations in systems, and the ways they are 'metabolised' by healthcare organisations, before proceeding to full-scale testing and implementation.

- Improve training of health professionals to deal with the challenges-both positive and negative-of innovation. ii. What support, training and systems will be needed before it can be introduced?

iii. How should we monitor the introduction?

By asking the first question, we may avoid the many disruptive innovations that are fashions rather than true improvements. By asking the second and third questions, we will smooth the transition. By thinking carefully and critically about when we should regard health systems reforms as 'clinical experiments' (and thus requiring the same level of evidence and oversight as other clinical interventions ${ }^{24}$ ) and when we should regard reforms as a normal part of the continuous experiential learning required to improve healthcare, we remain alert to the possible impacts-both negative and positive-of innovation.

These are all difficult challenges and require courage in the face of uncertainty, in the face of vested interests, in the face of immense political, patient and provider-led appetites and pressures, and in the face of financial squeeze and organisational and institutional inertia. Perhaps most importantly, these challenges require the courage to fail and learn. $^{25}$ In summary, quality improvement work needs to reconsider the role of innovation. In the long term, most elements in any medical system will be discarded and replaced. If we focus on making wise and courageous choices of innovations, introducing them with quality improvement principles in mind, then our future healthcare systems will better serve patients.

Competing interests None.

Provenance and peer review Not commissioned; externally peer reviewed.

\section{REFERENCES}

1. Greenhalgh T, Robert G, Macfarlane F, et al. Diffusion of innovations in service organizations: systematic review and recommendations. Milbank Q 2004;82:581-629.

2. Reid SV, Parys BOT. Long-term 5-year followup of the results of the vesica procedure. J Urol 2005;173:1234-6.

3. Milazzo S, Ernst E, Lejeune S, et al. Laetrile treatment for cancer. Cochrane Database Syst Rev 2006;(2):CD005476. doi:10.1002/ 14651858.CD005476.pub2.

4. Cochrane Injuries Group Reviewers. Human albumin administration in critically ill patients: systematic review of randomised controlled trials. BMJ 1998;317:235-40.

5. Davidoff F. Heterogeneity is not always noise: lessons from improvement. JAMA 2009;302:2580-6.

6. Tymstra T. The imperative character of medical technology and the meaning of 'anticipated decision regret.' Int J Technol Assess Health Care 1989;5:207-13.

7. Heinelt $\mathrm{H}$, Smith $\mathrm{R}$, eds. Sustainability, Innovation and Participatory Governance: A Cross-National Study of the EU Eco-Management and Audit Scheme. Aldershot: Ashgate, 2003.

8. Yanow D. Seeing organizational learning: a 'cultural' view. Organization 2000;7:247-68.

9. Rhodes R. The new governance: governing without government. Polit Stud 1996;XLIV:652-67.

10. Braithwaite J. The regulatory state. In: Rhodes R, Binder S, Rockman BA, eds. The Oxford Handbook of Political Institutions. Oxford: Oxford University Press, 2008.

11. Kickert WJM, Klijn E-H, Koppenjan JFN, eds. Managing Complex Networks: Strategies for the Public Sector. London: Sage, 1997.

12. Martin GP, Currie G, Finn R. Leadership, service reform, and publicservice networks: the case of cancer-genetics pilots in the English NHS. J Public Adm Res Theory 2009;19:769-94. 
13. Bate $\mathrm{P}$, Robert $\mathrm{G}$, Bevan $\mathrm{H}$. The next phase of healthcare improvement: what can we learn from social movements? Qual Saf Health Care 2004;13:62-6.

14. Bate P. Strategies for Cultural Change. Oxford: ButterworthHeinneman, 1994.

15. Glouberman S, Mintzberg $\mathrm{H}$. Managing the care of health and the cure of disease-Part I: differentiation. Health Care Manage Rev 2001;26:56-69.

16. Waring J, Currie G. Managing expert knowledge: organizational challenges and managerial futures for the UK medical profession. Organization Studies 2009; 30:755-78

17. Lowndes $\mathrm{V}$, Skelcher $\mathrm{C}$. The dynamics of multi-organizational partnerships. Public Adm 1998;76:313-33.

18. Adler PS, Koon SW, Heckscher C. Professional work: the emergence of collaborative community. Organ Sci 2008;19: $359-76$.
19. Pope C. Resisting evidence: the study of evidence-based medicine as a contemporary social movement. Health 2003;7:267-82.

20. McGuire M. Managing networks: propositions on what managers do and why they do it. Public Adm Rev 2002:62:599-609.

21. Orlikowski WJ. Using technology and constituting structures: a practice lens for studying technology in organizations. Organ $\mathrm{Sci}$ 2000;11:404-28.

22. Tversky A, Kahnemann D. The framing of decisions and the psychology of choice. Science 1981;211:453-8.

23. Leviton LC. External validity. In: Smelser NJ, Baltes PB, eds. The International Encyclopedia of the Social and Behavioral Sciences. Amsterdam: Elsevier, 2001.

24. Daniels N. Toward ethical review of health system transformations. Am J Public Health 2006;96:447-51.

25. Fox R, Swazey JP. The Courage to Fail: A Social View of Organ Transplants and Dialysis. New Brunswick NJ: Transaction Publishers, 2002. 